Review Article

\title{
Dietary Iron Intake in Pregnant Women in Europe: A Review of 24 Studies from 14 Countries in the Period 1991-2014
}

\author{
Nils Thorm Milman (iD \\ Department of Clinical Biochemistry, Noestved Hospital, University College Zealand, DK-4700 Noestved, Denmark \\ Correspondence should be addressed to Nils Thorm Milman; nils.milman@outlook.com
}

Received 3 November 2019; Accepted 3 February 2020; Published 25 February 2020

Academic Editor: Luigi Schiavo

Copyright (C) 2020 Nils Thorm Milman. This is an open access article distributed under the Creative Commons Attribution License, which permits unrestricted use, distribution, and reproduction in any medium, provided the original work is properly cited.

\begin{abstract}
Objective. Assessment of dietary iron intake in pregnant women in Europe. Design. Review. Setting. Literature search of dietary surveys reporting the intake of dietary iron using the PubMed and Google Scholar databases covering the years 1990-2019. Subjects. Healthy pregnant women. Results. 24 dietary surveys/studies in 14 European countries were included. Nine studies (38\%) used Food Frequency Questionnaires, which yielded significantly higher iron intake than studies using Dietary Records. Results from Dietary Record studies in 11 countries showed that iron intake varied between 8.3-15.4 mg/day with an estimated "median" value of 10-11 mg/day. Spain, Bosnia, and Poland reported an intake of 8.3-10.1 mg/day, Croatia, England, Norway, and Finland an intake of 10.2-11.4 mg/day, and Germany, Portugal, Czech Republic, and Greece an intake of 12.2-15.4 mg/day. The recommended iron intake in the various countries varied from $14.8-30 \mathrm{mg} /$ day. In all studies, $60-100 \%$ of the women had a dietary iron intake below the recommended intake. Conclusions. In Europe, the majority of pregnant women have a dietary iron intake, which is markedly below the recommended intake. This contributes to a low iron status in many pregnant women. Most guidelines do not advice routine iron supplements, while two guidelines (World Health Organization and Nordic Nutrition Recommendations) recommend routine iron supplementation during pregnancy. Within the European community, we need to reach consensus on the various guidelines and on the issue of iron supplementation. We should establish common European standardized dietary methods, uniform Dietary Reference Values, and uniform statistical methods in order to perform more reliable comparisons between studies in different countries.
\end{abstract}

\section{Introduction}

Body iron balance is a resultant of iron uptake vs. iron losses. In healthy humans, iron uptake is generated by gastrointestinal absorption of dietary iron [1]. In women of reproductive age, iron losses consist of obligatory or basal iron losses as well as physiological iron losses in association with menstruations $[2,3]$ and pregnancies $[4,5]$.

During pregnancy, there is a drastic physiologic increase in the need for uptake of iron compared to the nonpregnant period [5]. The need for absorbed iron increases from the 1st to the 3rd trimester with an average iron requirement in the entire gestation period of approximately $4.4 \mathrm{mg} /$ day [5].

An appropriate iron homeostasis or iron status is crucial for a normal function of all cells, tissues, and organs in the body. Both iron deficiency (ID) and iron overload will affect body functions in negative ways and impair the quality of life as well as life expectancy [6, 7]. ID and iron deficiency anemia (IDA) during pregnancy has negative effects on the health status of the mother and predisposes to complications during gestation and at delivery [8] as well as to postpartum anemia [9]. Iron is important for the normal development of the organs of the fetus, especially for the brain [10]. Furthermore, ID will affect the newborn baby, causing premature delivery and low birthweight [8].

The World Health Organization's (WHO) report on the global prevalence of anemia [11] states that in the European region, among pregnant women $15-49$ years of age, between $20.0-39.9 \%$ have anemia. The mean prevalence of anemia is $24.5 \%$ (95\% confidence interval $17.8-33.8 \%$ ). The predominant cause of anemia is ID [11]. 
The high physiological need for iron poses demands on the dietary intake and absorption of iron, which in turn are dependent on both the quantitative and qualitative dietary iron intake. In Europe, approximately $40 \%$ of women of reproductive age have small or absent body iron reserves, i.e., serum ferritin values $<30 \mu \mathrm{g} / \mathrm{L}$ [12]. The low iron status in these women is in part due to a low and inadequate dietary iron intake when hold against the recommended intake, as shown in a recent review article [13]. Among Danish women of reproductive age, only $20-30 \%$ have adequate body iron reserves, i.e., serum ferritin $>60-70 \mu \mathrm{g} / \mathrm{L}$ [14], making it possible for them to go through a pregnancy without taking iron supplements and without developing ID and IDA.

Among ethnic Danish pregnant women not taking supplemental iron, many develop ID and approximately $25 \%$ develop IDA $[5,14]$. This indicates that dietary iron intake and iron absorption in the majority of pregnant women are inadequate and do not fulfill the normal physiological requirements.

We know that a large fraction of nonpregnant women of reproductive age in Europe have an inadequate dietary iron intake [13]. How is the situation when they become pregnant? Do they change their dietary habits and increase their intake of dietary iron? Or do they continue with their habitual prepregnancy diet?

The purpose of this paper is to provide a review of dietary surveys assessing dietary iron intake in pregnant women in Europe and to examine to which degree iron intake may fulfill the demands of the recommended intake.

\section{Methods}

Literature search was performed in PubMed using the $\mathrm{MeSH}$ Database terms (iron, dietary AND women, pregnant) and in Google Scholar using the terms "iron, dietary," and "pregnancy" or "pregnant women." The search yielded 1,020 articles from different parts of the world. European studies, performed in the period 1990-2019, which reported the dietary intake of micronutrients and iron per se in healthy pregnant women, were included in this review.

As shown in our previous paper on dietary intake in women of reproductive age in Europe [13], dietary surveys using the Food Frequency Questionnaire (FFQ) method overestimate the dietary iron intake [15]. Therefore, we decided a priori not to include studies using FFQs. However, during the literature search, it became evident that the total number of studies was small and that 9 out of the 24 identified studies (38\%) used FFQs exclusively. In order to provide the reader with a more comprehensive overview of the available data, we subsequently decided to include the FFQ studies.

In the statistical interpretation of the results, it is important to consider the frequency distribution of dietary iron intake. If the distribution is normal, it is relatively simple to define and calculate inadequate intake using parametric statistics (arithmetic mean and standard deviation (SD)). In case of an asymmetric distribution skewed to the right, e.g., with a relatively higher frequency of low values and a relatively lower frequency of high values, the median is lower than the arithmetic mean. Therefore, using the arithmetic mean in skewed data will tend to underestimate the prevalence of inadequate iron intake, and instead nonparametric statistics (median and percentiles) should be used [13]. In studies, where medians and percentiles are presented, these are quoted. In studies not presenting medians and percentiles, arithmetic means and SDs are quoted instead.

\section{Results}

Most reports were in English language, a few reports in other languages were translated into English. An overview of the 24 included European surveys/studies on dietary iron intake in pregnant women performed in 14 countries during the years 1991 to 2014 is shown in Table 1 [16-39]. The two Finnish reports $[19,20]$ contained the same sample of women but were analyzed using different dietary aspects and should be considered as being one study.

The age of the women ranged 18 to 42 years. In most studies the mean age was around 30 years.

The dietary survey methods varied between the 24 studies (Table 1). The most common dietary method was FFQ, being used in 9 studies; 3-7 day food diary being used 8 studies and 24-hour dietary recall performed 1-3 times being used in 6 studies. Four studies [19, 28, 31, 36] performed 3-5 day food diary concomitantly with an FFQ, and one study used 24 -hour recall $\times 2$ concomitantly with an FFQ [38].

The food composition tables being used to calculate dietary iron intake were in most countries based on national food databases, but a Greek [23] and one Spanish study [33] used food composition tables from USA and the second Spanish study used tables from France [32] in the calculation of micronutrient intake.

In Table 1, the studies are arranged in alphabetic order according to the country. In Table 2, where the FFQ studies are excluded, the studies are arranged according to the magnitude of median or mean dietary iron intake.

Among all the studies (FFQs plus Dietary Records), the Czech Republic, Finland, Germany, Greece, Portugal, and Spain (INMA-Valencia) reported a median or mean dietary iron intake ranging from 11.4 to $20.4 \mathrm{mg} /$ day. In Norway, England, Croatia, and Poland, iron intake was approximately 10-11 mg/day, and in Bosnia and Spain (Reus), the intake was below $9 \mathrm{mg} /$ day. In the studies using Dietary Records, the dietary iron intake in 11 countries varied between $8.1-15.4 \mathrm{mg} /$ day as shown in Table 2; the estimated "median" value of dietary iron intake in the 11 countries was $10-11 \mathrm{mg} /$ day. Dietary iron intake in nonpregnant women of reproductive age in the respective countries is shown as well $[16,40-45]$. Clearly, the dietary iron intake in pregnant women did not differ significantly compared with the intake in nonpregnant women.

Five studies evaluated the results of FFQs against the results of food diary and 24-hour recall methods $[19,28,31,36,38]$. In all these studies, intake of nutrients and iron was significantly higher in the FFQ studies than in the Dietary Record studies with $p$ values ranging from $p<0.01$ $[31,36,38]$ to $p<0.05$ [28]. Median or mean values for 


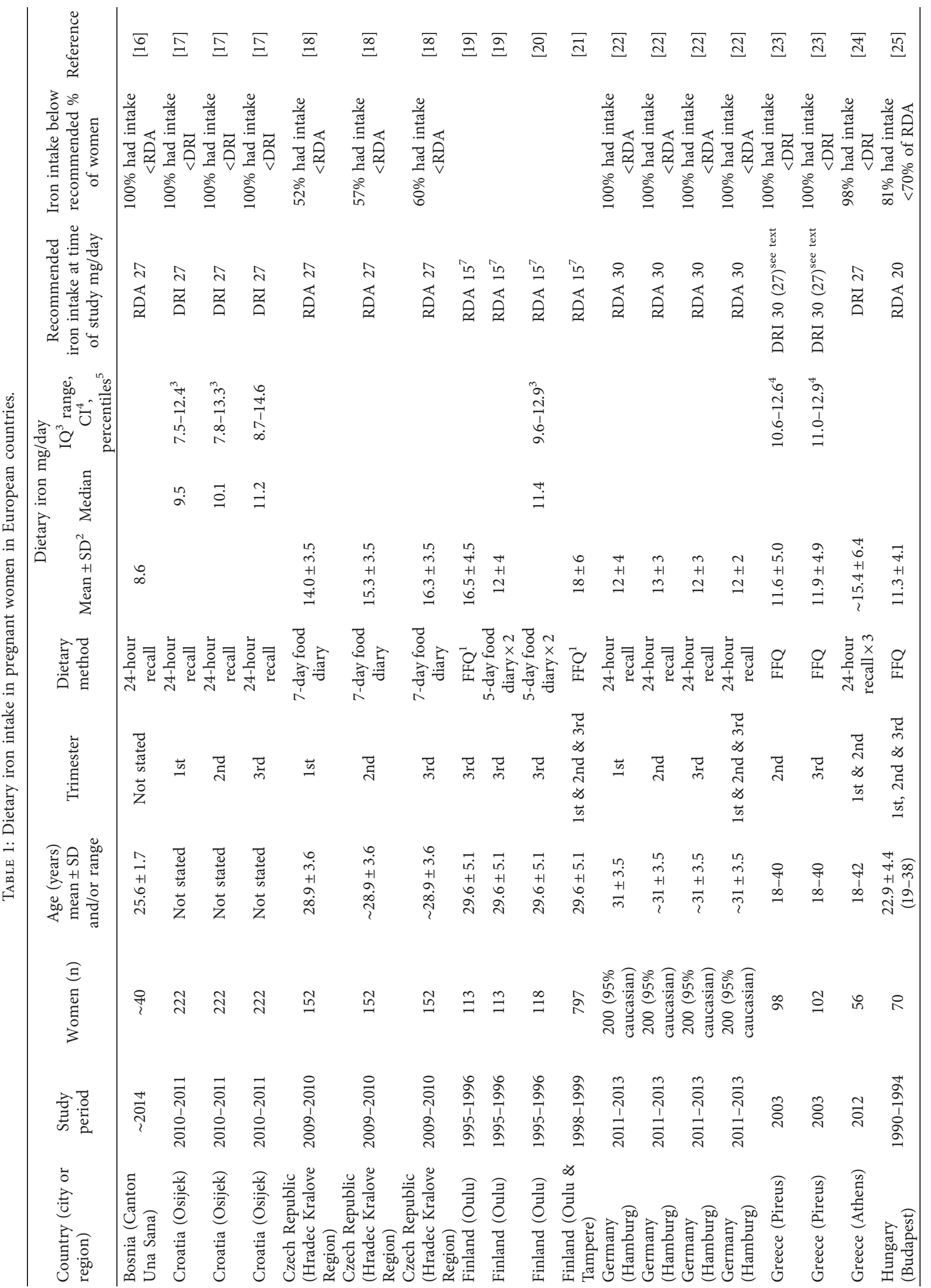




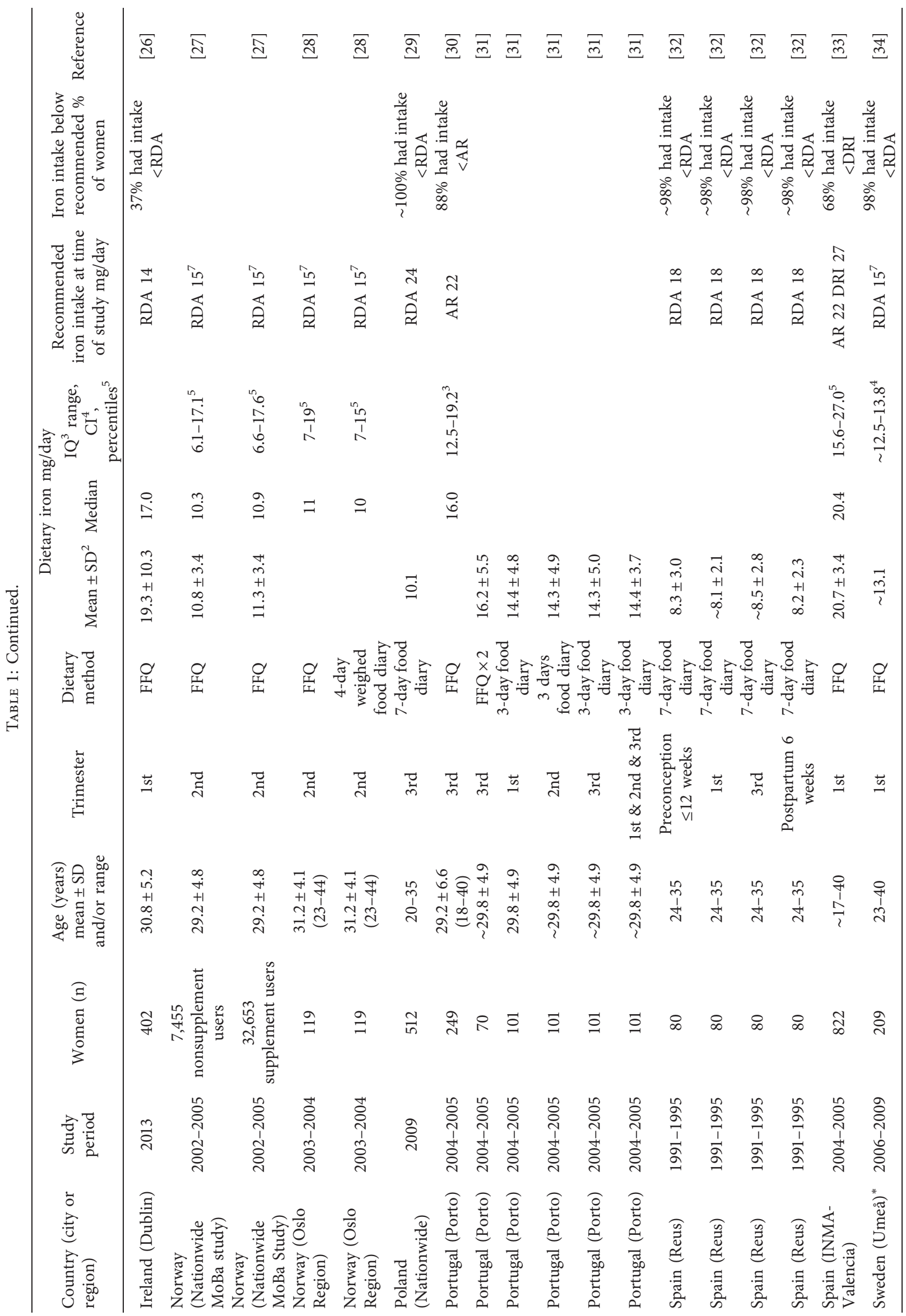




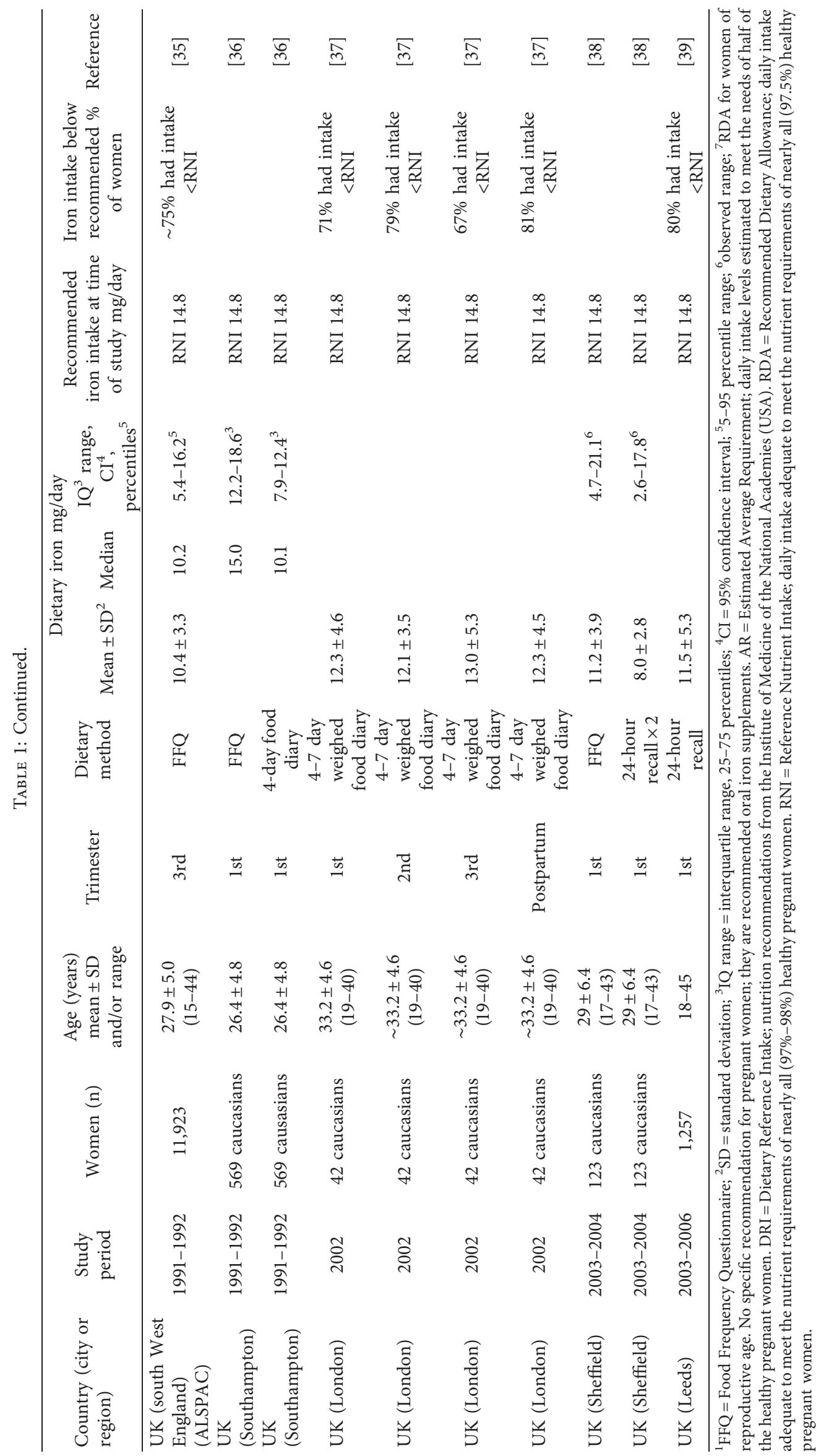


TABLE 2: Dietary iron intake in pregnant women in 11 European countries arranged according to the magnitude of median or mean iron intake. For comparison, iron intake in nonpregnant women of reproductive age in the same countries is shown as well. Only studies using dietary record methods are included.

\begin{tabular}{|c|c|c|c|c|}
\hline Country & $\begin{array}{l}\text { Median or mean* dietary iron intake in } \\
\text { pregnant women } \mathrm{mg} / \text { day }\end{array}$ & Reference & $\begin{array}{c}\text { Median or mean* dietary iron intake in } \\
\text { nonpregnant women } \mathrm{mg} / \text { day }\end{array}$ & Reference \\
\hline Greece & $15.4^{a+b^{*}}$ & [24] & & \\
\hline Czech & $14.0^{a^{*}} ; 15.3^{b^{*}} ; 16.3^{c^{*}}$ & [18] & & \\
\hline $\begin{array}{l}\text { Republic } \\
\text { Portugal }\end{array}$ & $14.4^{a+b+c^{*}}$ & [31] & & \\
\hline Germany & $12.2^{a+b+c^{*}}$ & {$[22]$} & 12.2 & {$[40]$} \\
\hline Finland & $11.4^{c}$ & {$[20]$} & 10.3 & {$[41]$} \\
\hline Norway & $11^{b^{*}} ; 11^{c^{*}} ; 10^{b}$ & {$[28]$} & 10.0 & {$[42]$} \\
\hline England & $10.1^{a} ; 8.0^{a^{*}} ; 11.5^{a^{*}}$ & {$[36,38,39]$} & 9.5 & {$[43]$} \\
\hline Croatia & $9.5^{a} ; 10.1^{b} ; 11.2^{c}$ & [17] & & \\
\hline Poland & $10.1^{c^{*}}$ & [29] & $10.7^{*}$ & {$[44]$} \\
\hline Bosnia & $8.6^{*}$ & {$[16]$} & $7.6^{*}$ & {$[16]$} \\
\hline Spain & $8.3^{a^{*}} ; 8.5^{c^{*}}$ & [32] & $10.5^{*}$ & [45] \\
\hline
\end{tabular}

*Arithmetic mean, $a=1$ st trimester; $b=2$ nd trimester; $c=3$ rd trimester.

dietary iron intake in mg/day in FFQ studies versus Dietary Record studies were 16.5 versus 12 [19], 11 versus 10 [28], 16.2 versus 14.3 [31], 15 versus 10.1 [36], and 11.2 versus $8 \mathrm{mg} /$ day [39]. The correlations between iron intake in FFQ and Dietary Record studies were weak with crude Pearson correlation coefficients $(r)$ ranging from $0.27-0.32$ $[19,28,36,38]$ and 0.43 [31]; when adjusted for energy intake, the coefficients increased slightly to $0.41-0.56$ $[19,28,31,36]$.

The discrepancy between FFQ and Dietary Record methods was clearly shown in the Swedish study [34]. The reference group of nonpregnant women $(n=206)$ had a dietary iron intake of mean $14.5 \mathrm{mg} /$ day [34], which was significantly higher compared to a mean of $9.4 \mathrm{mg} /$ day in the large Nationwide Swedish study using 4-day food diary $[13,46]$. The authors concluded "that there was some uncertainty concerning the dietary records." In Spain, the INMA-Valencia FFQ study reported a mean iron intake of $20.7 \mathrm{mg} /$ day [33] in contrast to the 7-day food diary study from nearby Reus reporting a mean intake of approximately $8.3 \mathrm{mg} /$ day [32].

The Croatian and Czech studies [17, 18] reported a significant increase in energy, macronutrient, and micronutrient intake including iron, during the three trimesters $(p<0.001)$. In contrast, the studies from Germany [22], Greece (Pireus) [23], Hungary [25], Portugal [31], Spain (Reus) [32], and England (London) [37] showed no statistically significant differences between nutrient and iron intake in the various trimesters.

Three studies $[24,26,27]$ included the energy intake in the selection criteria of the women. In the Greek [24] and Norwegian studies [27], only women with a habitual energy intake between 4.5 and $20 \mathrm{MJ} /$ day were included as suggested in an Australian study [47]. In the Irish study [26] under-reporters and over-reporters of energy intake, in total 122 out of 524 (23\%) women, were excluded from the study.

Heme iron intake in percentage of total iron intake was reported in the Croatian study, being $15.8 \%, 16.4 \%$, and $16.6 \%$ in the 1 st, $2 \mathrm{nd}$, and $3 \mathrm{rd}$ trimester, respectively [17]. In the study from Leeds, heme iron constituted 5.2\% of dietary iron intake [39].

The nutrient density for iron was reported only in the Irish study, being median $17.0 \mathrm{mg}$ per $10 \mathrm{MJ}$ (mean $19.5 \pm 0.8$ (SD)) [26], which is among the highest nutrient densities reported in Europe [13].

The Norwegian MoBa study recorded the use of dietary supplements [27]. Among the women, 22\% recorded the use of an iron supplement per se and a further 25\% took supplemental iron contained in a multivitamin-multimineral tablet. Women using any kind of supplement had a significantly higher dietary iron intake than nonsupplement users $(p<0.001)$ (see Table 1$)$.

The Average Requirement (AR) is the level of daily nutrient intake that is estimated to be adequate for half of the people in a population group, provided a normal distribution of requirement [48]. Two studies from Portugal [30] and Spain [33] quoted the AR, with an estimated value of $22 \mathrm{mg}$ iron/day. Provided an AR of $22 \mathrm{mg} /$ day for dietary iron intake in pregnant women, more than $60-80 \%$ of women in all the countries had an intake below AR, in some countries up to $100 \%$ (Table 1 ).

In the various studies, there was no consistency in the terminology and the use of Dietary Reference Values (DRV) for dietary iron intake [48]. Eight studies quoted the Recommended Dietary Allowance (RDA), 6 studies the Reference Nutrient Intake (RNI), 4 studies the Dietary Reference Intake (DRI), and two studies the AR.

The recommended intake of dietary iron in pregnant women by the national nutrition boards displayed major differences between countries, varying from $14 \mathrm{mg} /$ day in Ireland [26] to $14.8 \mathrm{mg} /$ day in UK [39], $15 \mathrm{mg}$ in Norway [27] and Sweden [34], $18 \mathrm{mg} /$ day in Spain [32], and $30 \mathrm{mg} /$ day in Germany [23] (see Table 1).

Table 1 shows the Dietary Record studies, which assessed the percentage of women having an iron intake below the recommend intake. This fraction was dependent on the national recommended intake being hold against the actual intake and therefore varied between countries, with an overall range of $60-100 \%$. 
When median iron intake is below the recommended intake, this indicates that more than $50 \%$ of the women have an iron intake below the recommended intake. In all the Dietary Record studies, median iron intake was considerably lower than the recommended intake, indicating that more than $50 \%$ of the women had an inadequate iron intake.

\section{Discussion}

In the reported Dietary Record studies, dietary iron intake was distinctly below the recommend intake in $60-100 \%$ of pregnant women. This finding was evident even in countries (Finland, Norway, Sweden, and England), which recommend the same iron intake in pregnant as in nonpregnant women of reproductive age. One exception was the Irish FFQ study, which reported a median dietary iron intake of $17.0 \mathrm{mg} /$ day (mean $19.3 \mathrm{mg} /$ day), indicating that approximately $37 \%$ had an intake below the RDA of $14 \mathrm{mg} /$ day [26]. However, this was an FFQ study, which excluded a considerable number of women with nonplausible energy intake, and the RDA for iron was the lowest recommended value reported among the European countries in this paper. For comparison, mean dietary iron intake in women of reproductive age in Ireland assessed by Dietary Records was $10.1 \mathrm{mg} /$ day in the NSIFCS study and $13.7 \mathrm{mg} /$ day in the NANS study [49], clearly being significantly lower than the reported intake in pregnant women [26].

The exclusion of women with nonplausible low energy intake pushes the population median and mean intake upwards but might be necessary to get a "true" picture of what intake is in this population. Energy intake criteria for inclusion were also used in the Greek [24] and Norwegian [27] studies.

The DRI value of $30 \mathrm{mg} /$ day used in one Greek study [23] is due to a quotation error and should instead be $27 \mathrm{mg} /$ day. The authors state that this value is recommend by the Institute of Medicine (IOM) [50], but actually it has been taken from a position paper from the American Dietary Association [51], which does not quote the IOM but quotes the recommendation from the Centers for Disease Control and Prevention (CDC) stating that all pregnant women should take an iron supplement of $30 \mathrm{mg}$ /day during pregnancy [52].

The studies covered a time period of more than 25 years, and it appears that the overall dietary iron intake was quite constant during this period.

Four studies $[23,25,31,32]$ reported that dietary iron intake was constant during the three trimesters of pregnancy, indicating that most women do not to any significant extent change their dietary habits during pregnancy. In contrast, the Croatian [17] and Czech [18] studies reported a significant increase in energy, macro- and micronutrient intake including iron during pregnancy, probably reflecting country specific dietary habits and/or recommendations from the antenatal health authorities.

In the various countries, dietary iron intake was quite similar in pregnant and nonpregnant women of reproductive age (Table 2). The studies from Reus [32] and London [37] showed that iron intake was not significantly different prior to pregnancy, during gestation, and in the postpartum period. This indicates that most women do not to any significant extent change their dietary habits when they become pregnant but continue with their habitual prepregnancy diet during pregnancy.

The various designs of the studies and the different dietary methods impede direct comparison of the results. Clearly, when comparing FFQs and Dietary Records, dietary iron intake was significantly higher in FFQs than in Dietary Records and with low correlation coefficients (see above). This finding has previously been reported in nonpregnant women of reproductive age in Europe [13]. However, our findings are in contrast with the conclusions of a previous review paper, which evaluated different dietary methods for assessment of micronutrient intake in pregnant women, and concluded that "FFQs were good for measuring both shortterm and long-term intake of iron" [53].

The European Food Consumption Survey Method (EFCOSUM) group has concluded that "the most suitable method to get internationally comparable new data on population means and distributions of actual intake is a 24hour recall, to be conducted at least twice" [54]. However, this method was used in only 6 studies.

National food composition tables reflect the composition of the most common staple foods consumed in a country. Usually, mandatory fortification of foods is included in the food composition tables, while optional fortification is not. There may in some countries exist foods which are ironfortified on a voluntary basis, and this iron will not be included in the food composition tables. Iron fortified foods will contribute to a higher iron nutrient density and consequently to a higher dietary iron intake [13]. This could in part explain the differences in dietary iron intake across Europe.

Countries have different recommendations concerning iron fortification of foods. For example, UK has mandatory fortification of wheat flour with iron. Many breakfast cereals are fortified with iron on an optional basis and according to the British National Diet and Nutrition Survey contribute to $20 \%$ of the average iron intake in British adults. Fortification practices in Europe in 2006 were as follows: Denmark, Finland, Germany, Ireland, Italy, the Netherlands, and Spain had no mandatory iron fortification, but optional fortification with iron is occasionally used, especially in flour and breakfast cereals [55].

In the Norwegian MoBa study [27], users of any dietary supplement had a higher dietary iron intake than nonusers, probably due to more healthy dietary habits, because supplement users had a higher educational level, a lower frequency of smoking, and a higher frequency of normal body weight prior to pregnancy.

The frequency distribution of dietary iron intake in a population does not show a normal distribution, but a distribution, which is skewed to the right [13], with an overweight of high values. Therefore, median values are consistently lower than arithmetic values as shown in four studies $[26,27,33,35]$. The distribution is therefore most accurately described using nonparametric statistics (median and percentiles) or using logarithmic values in the 
TABle 3: Dietary Reference Values for iron. Reference Nutrient Intake and Average Requirement for dietary iron in pregnant women compared with nonpregnant women of reproductive age.

\begin{tabular}{|c|c|c|c|c|c|c|}
\hline \multirow[t]{2}{*}{ Institution } & \multicolumn{2}{|c|}{$\begin{array}{l}\text { DRV for iron in } \\
\text { pregnant women } \\
\text { mg/day }\end{array}$} & \multirow[t]{2}{*}{ During pregnancy } & \multicolumn{2}{|c|}{$\begin{array}{l}\text { DRV for iron in } \\
\text { nonpregnant } \\
\text { women } \mathrm{mg} / \text { day }\end{array}$} & \multirow[t]{2}{*}{ Reference } \\
\hline & RNI & $\mathrm{AR}$ & & RNI & $\mathrm{AR}$ & \\
\hline IOM 2001 & 27 & 22 & & 18 & 5 & {$[50]$} \\
\hline FAO \&WHO 2001 & $19.6^{*}$ & & Iron supplement recommended & $19.6^{*}$ & & {$[56]$} \\
\hline NNR 2012 & 15 & 6 & Iron supplement recommended & 15 & 6 & {$[57]$} \\
\hline EFSA 2015 & 16 & 6 & & 16 & 6 & {$[58,59]$} \\
\hline SACN 2017 & 14.8 & 11.4 & & 14.8 & 11.4 & {$[60]$} \\
\hline
\end{tabular}

${ }^{*}$ Provided $15 \%$ bioavailability of dietary iron. DRV = Dietary Reference Value. RNI = Reference Nutrient Intake. AR = Average Requirement. IOM = Institute of Medicine (USA). FAO = Food and Agriculture Organization of the United Nations. WHO $=$ World Health Organization. NNR $=$ Nordic Nutrition Recommendations. EFSA = European Food Safety Authority. SACN = Scientific Advisory Committee on Nutrition (UK).

calculation of the geometric mean and standard deviation [13]. Using the arithmetic mean will underestimate the frequency of individuals with an inadequate iron intake.

National and international recommendations for dietary iron intake are shown in Table 3.

RNI and AR for dietary iron in pregnant women are compared with RNI and AR for nonpregnant women of reproductive age in the respective countries [50, 56-60]. Obviously, there is no consensus on the recommended intake. The IOM [50] advocates for an increased dietary iron intake in pregnancy, while the other institutions [56-60] recommend the same intake in pregnant and nonpregnant women.

However, the CDC [52], the Food and Agricultural Organization of the United Nations (FAO), and WHO [56] as well as the Nordic Nutrition Recommendations (NNR) [57] conclude that an adequate iron intake cannot be obtained solely by changes in dietary habits and therefore recommend iron supplements during pregnancy. In contrast, the European Food Safety Authority (EFSA) [58, 59] and the Scientific Advisory Committee on Nutrition (SACN) [60] do not recommend supplementary iron to pregnant women as routine prophylaxis but argue that treatment with iron should be reserved to women with confirmed ID or IDA.

In nonpregnant Chinese women of reproductive age, the average physiological requirements for absorbed iron measured by a stable iron isotope method and using linear regression is approximately $1.29 \mathrm{mg} / \mathrm{day}(20.98 \mu \mathrm{g} / \mathrm{kg}$ body weight/day after adjustment for body mass) [61]. The calculated AR for iron is approximately 11 to $13 \mathrm{mg}$ /day and the RNI is between 15 to $18 \mathrm{mg} /$ day [61].

The physiological need for absorbed iron during normal pregnancy is substantial and increases gradually during gestation from approximately $1 \mathrm{mg} /$ day in the 1 st trimester to $7.5 \mathrm{mg} /$ day in the $3 \mathrm{rd}$ trimester [5]. The extra iron is needed in order to expand the woman's red cell mass and to secure an adequate iron supply for a normal function of the placenta and the development of the growing fetus. The total gross need for iron in a normal pregnancy is $1,000-1,200 \mathrm{mg}$ with a net need of approximately 500-600 mg [5]. Women with prepregnancy body iron reserves of approximately $500 \mathrm{mg}$ corresponding to a serum ferritin level of $60-70 \mu \mathrm{g} / \mathrm{L}$ will be able to go through a normal pregnancy without taking iron supplements and without getting ID or IDA [14]. Among Danish women with prepregnancy ferritin levels below $60-70 \mu \mathrm{g} / \mathrm{L}$, who are not taking iron supplements, approximately $75 \%$, develop ID and $20-25 \%$ IDA [62].

The study from Leeds found a positive relationship between the total iron intake (dietary plus supplemental iron) in early pregnancy and the birthweight of the newborns [39].

In the assessment of iron status in pregnant women, it is important to distinguish between iron-supplemented and nonsupplemented women. An overview of iron status studies in pregnant women in Europe who were not taking iron supplements have recently been published [12]; median serum ferritin levels in these studies ranged 5-21 $\mu \mathrm{g} / \mathrm{L}$ ("estimated" median value $10 \mu \mathrm{g} / \mathrm{L}$ ); the frequency of ID ranged $35-83 \%$ ("estimated" median value 50\%) and the frequency of IDA ranged 12-49\% ("estimated" median value $26 \%)$. In women not taking iron supplements, the frequency of ID and IDA typically increases gradually during pregnancy and peaks in mid or late 3rd trimester [62].

In contrast, iron-supplemented pregnant women had a higher iron status than nonsupplemented women; median serum ferritin levels in the iron supplemented women ranged $15-63 \mu \mathrm{g} / \mathrm{L}$ ("estimated" median value $21 \mu \mathrm{g} / \mathrm{L}$ ); the frequency of ID ranged $0-41 \%$ ("estimated" median value $4 \%$ ) and the frequency of IDA ranged 0-27\% ("estimated" median value 5\%) [12]. Thus, the prevalence of ID and IDA was markedly lower in iron-supplemented women compared with nonsupplemented women [12].

The low dietary iron intake in pregnant women has motivated the CDC [52], FAO \& WHO [56], and NNR [57] guidelines to recommend routine iron prophylaxis during pregnancy. In Denmark, all pregnant women are recommended a supplement of $40-50 \mathrm{mg}$ elemental iron/day at their first visit to the antenatal clinic and the compliance is high, close to $80 \%$ [63].

From a physiological point of view, individual iron prophylaxis should be encouraged instead of general routine prophylaxis [14], because $20-30 \%$ of the pregnant women in fact do not need iron supplements and consequently are "overtreated." Routine evaluation of iron status (serum ferritin and serum transferrin saturation) in pregnant 
women at their first check-up in the antenatal clinic can identify women who should be prescribed iron supplements [14]. This approach is recommended by the Danish Society of Obstetrics and Gynecology [64] but has still not been implemented by the Danish Health Authority.

4.1. Limitations of This Review. This review has limitations, mainly due to the heterogeneous methods used in the studies. All but one study [27] were regional and do not reflect the nutritional situation in the entire country. The dietary methods differed between studies, statistical methods were different, most studies used parametric and a few nonparametric statistics, few studies had been corrected for under- and over-reporting, and furthermore, there was an inconsistent terminology concerning the use of DRVs of dietary iron. These are all factors, which impair comparison of the results of the various studies. Furthermore, the food composition tables varied between countries, and the contribution of mandatory and/or voluntary food iron fortification was not evaluated in the studies.

\section{Conclusions}

This review demonstrates that in Europe, most women do not change their dietary habits during pregnancy and women consume the same amounts of micronutrients before, during, and after pregnancy. It is important to recognize that a high proportion of pregnant women, in several studies $80-100 \%$, has a dietary iron intake, which is below the recommended intake. The relatively low iron intake contributes to the low body iron status found in many pregnant women not taking iron supplements $[12,62]$. This has motivated several advisory institutions to recommend routine iron supplementation during pregnancy $[52,56,57]$. However, few European countries follow these recommendations. In Denmark, the National Health Authority has successfully implemented this recommendation as a mandatory procedure in the antenatal health care system [65].

In European countries and within the European Union, there is a need to obtain consensus between the various guidelines and the conflicting issue of iron supplementation. Furthermore, there is a need for implementation of common standardized Dietary Record methods [54] and for standardization of food composition tables as initiated by EFSA [66]. It is also important to reach consensus on the use of the different DRVs [48] and to implement the use of uniform statistical methods in order to perform more reliable intraand intercountry comparison of dietary intake.

\section{Conflicts of Interest}

The author declares that there are no conflicts of interest.

\section{Acknowledgments}

This research was supported by an unrestricted grant from Pharmovital Aps, Rosenkæret 11B, DK-2860 Søborg, Denmark.

\section{References}

[1] G. J. Anderson and D. M. Frazer, "Current understanding of iron homeostasis," The American Journal of Clinical Nutrition, vol. 106, no. Suppl 6, pp. S1559-S1566, 2017.

[2] L. Hallberg, L. Nilsson, A. M. Höghdal, and G. Rybo, "Menstrual blood losses in a population sample," Acta Obstetricia et Gynecologica Scandinavica, vol. 43, no. Suppl 7, p. 57, 1965.

[3] N. Milman, N. Rosdahl, N. Lyhne, T. Jørgensen, and N. Graudal, "Iron status in Danish women aged 35-65 years: relation to menstruation and method of contraception," Acta Obstetricia et Gynecologica Scandinavica, vol. 72, no. 8, pp. 601-605, 1993.

[4] N. Milman, M. Kirchhoff, and T. JØrgensen, "Iron status markers, serum ferritin and hemoglobin in 1359 Danish women in relation to menstruation, hormonal contraception, parity, and postmenopausal hormone treatment," Annals of Hematology, vol. 65, no. 2, pp. 96-102, 1992.

[5] N. Milman, "Iron and pregnancy-a delicate balance," Annals of Hematology, vol. 85, no. 9, pp. 559-565, 2006.

[6] L. Percy, D. Mansour, and I. Fraser, "Iron deficiency and iron deficiency anaemia in women," Best Practice \& Research Clinical Obstetrics \& Gynaecology, vol. 40, pp. 55-67, 2017.

[7] N. T. Milman, F. V. Schioedt, A. E. Junker, and K. Magnussen, "Diagnosis and treatment of genetic HFE-hemochromatosis: the Danish aspect," Gastroenterology Research, vol. 12, no. 5, pp. 221-232, 2019.

[8] C. Breymann, "Iron deficiency anemia in pregnancy," Seminars in Hematology, vol. 52, no. 4, pp. 339-347, 2015.

[9] N. Milman, "Postpartum anemia I: definition, prevalence, causes, and consequences," Annals of Hematology, vol. 90, no. 11, pp. 1247-1253, 2011.

[10] V. Markova, C. Holm, A. Pinborg, L. Thomsen, and T. Moos, "Impairment of the developing human brain in iron deficiency: correlations to findings in experimental animals and prospects for early intervention therapy," Pharmaceuticals, vol. 12, no. 3, p. 120, 2019.

[11] World Health Organization, The Global Prevalence of Anaemia in 2011, World Health Organization, Geneva, Switzerland, 2015.

[12] N. Milman, C. L. Taylor, J. Merkel, and P. M. Brannon, "Iron status in pregnant women and women of reproductive age in Europe," The American Journal of Clinical Nutrition, vol. 106, no. 6, pp. 1655S-1688S, 2017.

[13] N. Milman, "Dietary iron intake in women of reproductive age in Europe: a review of 49 studies from 29 countries in the period 1993-2015," Journal of Nutrition and Metabolism, vol. 2019, Article ID 7631306, 13 pages, 2019.

[14] N. Milman, "Iron prophylaxis in pregnancy-general or individual and in which dose?" Annals of Hematology, vol. 85, no. 12 , pp. 821-828, 2006.

[15] V. Coathup, S. Wheeler, and L. Smith, "A method comparison of a food frequency questionnaire to measure folate, choline, betaine, vitamin $\mathrm{C}$ and carotenoids with 24-h dietary recalls in women of reproductive age," European Journal of Clinical Nutrition, vol. 70, no. 3, pp. 346-351, 2016.

[16] V. Alibabić, E. Šertović, I. Mujić, J. Živković, M. Blažić, and S. Zavadlav, "The level of nutrition and dietary iron intake of Bosnian women," Procedia-Social and Behavioral Sciences, vol. 217, pp. 1071-1075, 2016.

[17] I. Banjari, D. Kenjeric, and M. L. Mandic, "Iron bioavailability in daily meals of pregnant women," Journal of Food and Nutrition Research, vol. 52, pp. 203-209, 2013. 
[18] M. Hronek, P. Doubkova, D. Hrnciarikova, and Z. Zadak, "Dietary intake of energy and nutrients in relation to resting energy expenditure and anthropometric parameters of Czech pregnant women," European Journal of Nutrition, vol. 52, no. 1, pp. 117-125, 2013.

[19] M. Erkkola, M. Karppinen, J. Javanainen, L. Räsänen, M. Knip, and S. M. Virtanen, "Validity and reproducibility of a food frequency questionnaire for pregnant Finnish women," American Journal of Epidemiology, vol. 154, no. 5, pp. 466476, 2001.

[20] M. Erkkola, M. Karppinen, A. Järvinen, M. Knip, and S. Virtanen, "Folate, vitamin D, and iron intakes are low among pregnant Finnish women," European Journal of Clinical Nutrition, vol. 52, no. 10, pp. 742-748, 1998.

[21] T. Arkkola, U. Uusitalo, M. Pietikäinen et al., "Dietary intake and use of dietary supplements in relation to demographic variables among pregnant Finnish women," British Journal of Nutrition, vol. 96, no. 5, pp. 913-920, 2006.

[22] A. Diemert, S. Lezius, M. Pagenkemper et al., "Maternal nutrition, inadequate gestational weight gain and birth weight: results from a prospective birth cohort," BMC Pregnancy and Childbirth, vol. 16, no. 1, p. 224, 2016.

[23] G. Petrakos, P. Panagopoulos, I. Koutras et al., "A comparison of the dietary and total intake of micronutrients in a group of pregnant Greek women with the Dietary Reference Intakes," European Journal of Obstetrics \& Gynecology and Reproductive Biology, vol. 127, no. 2, pp. 166-171, 2006.

[24] K. Hatzopoulou, V. Filis, M. G. Grammatikopoulou, C. Kotzamanidis, and M. Tsigga, "Greek pregnant women demonstrate inadequate micronutrient intake despite supplement use," Journal of Dietary Supplements, vol. 11, no. 2, pp. 155-165, 2014.

[25] M. Antal, A. Regöly-Mérei, H. Varsányi et al., "Nutritional survey of pregnant women in Hungary," International Journal for Vitamin and Nutrition Research, vol. 67, pp. 115-122, 1997.

[26] L. Mullaney, S. Cawley, R. Kennedy, A. C. O'Higgins, D. McCartney, and M. J. Turner, "Maternal nutrient intakes from food and drinks consumed in early pregnancy in Ireland," Journal of Public Health, vol. 39, pp. 754-762, 2017.

[27] M. Haugen, A. L. Brantsæter, J. Alexander, and H. M. Meltzer, "Dietary supplements contribute substantially to the total nutrient intake in pregnant Norwegian women," Annals of Nutrition and Metabolism, vol. 52, no. 4, pp. 272-280, 2008.

[28] A. L. Brantsaeter, M. Haugen, J. Alexander, and H. M. Meltzer, "Validity of a new food frequency questionnaire for pregnant women in the Norwegian Mother and Child Cohort Study (MoBa)," Maternal \& Child Nutrition, vol. 4, no. 1, pp. 28-43, 2008.

[29] I. Bojar, A. Owoc, E. Humeniuk, W. Wierzba, and A. Fronczak, "Inappropriate consumption of vitamins and minerals by pregnant women in Poland," Annals of Agricultural and Environmental Medicine: AAEM, vol. 19, pp. 263-266, 2012.

[30] E. Pinto, H. Barros, and I. d. S. Silva, "Dietary intake and nutritional adequacy prior to conception and during pregnancy: a follow-up study in the north of Portugal," Public Health Nutrition, vol. 12, no. 7, pp. 922-931, 2008.

[31] E. Pinto, M. Severo, S. Correia et al., "Validity and reproducibility of a semi-quantitative food frequency questionnaire for use among Portuguese pregnant women," Maternal \& Child Nutrition, vol. 6, pp. 105-119, 2009.

[32] V. Arija, G. Cucó, J. Vila, R. Iranzo, and J. Fernández-Ballart, "Consumo, hábitos alimentarios y estado nutricional de la población de Reus en la etapa preconcepcional, el embarazo y el posparto," Medicina Clínica, vol. 123, no. 1, pp. 5-11, 2004.

[33] C. L. Rodrıguez-Bernal, R. Ramón, J. Quiles et al., "Dietary intake in pregnant women in a Spanish Mediterranean area: as good as it is supposed to be?," Public Health Nutrition, vol. 16, no. 8, pp. 1379-1389, 2013.

[34] A. Lundqvist, I. Johansson, A. L. Wennberg et al., "Reported dietary intake in early pregnant compared to non-pregnant women-a cross-sectional study," BMC Pregnancy and Childbirth, vol. 14, no. 1, p. 373, 2014.

[35] I. Rogers and P. Emmett, "Diet during pregnancy in a population of pregnant women in South West England," European Journal of Clinical Nutrition, vol. 52, no. 4, pp. 246-250, 1998.

[36] S. Robinson, K. Godfrey, C. Osmond, V. Cox, and D. Barker, "Evaluation of a food frequency questionnaire used to assess nutrient intake in pregnant women," European Journal of Clinical Nutrition, vol. 50, no. 5, pp. 302-308, 1996.

[37] E. Derbyshire, G. J. Davies, V. Costarelli, and P. W. Dettmar, "Habitual micronutrient intake during and after pregnancy in Caucasian Londoners," Maternal \& Child Nutrition, vol. 5, no. 1, pp. 1-9, 2009.

[38] T. Moratidou, F. Ford, and R. B. Fraser, "Validation of a foodfrequency questionnaire for use in pregnancy," Public Health Nutrition, vol. 9, pp. 515-522, 2006.

[39] N. A. Alwan, D. C. Greenwood, N. A. B. Simpson, H. J. McArdle, K. M. Godfrey, and J. E. Cade, "Dietary iron intake during early pregnancy and birth outcomes in a cohort of British women," Human Reproduction, vol. 26, no. 4, pp. 911-919, 2011.

[40] N. Verzehrsstudie II, "Ergebnisbericht, Teil 2. Die bundesweite Befragung zur Ernährung von Jugendlichen und Erwachsenen. Max-Rubner Institut. Bundesforschungsinstitut für Ernährung und Lebensmittel (National Food Consumption Study II," Report of Results, Part 2. The Nationwide Survey on the Nutrition of Adolescents and Adults, Max-Rubner Institute. Federal Research Institute of Nutrition and Food), Karlsruhe, Germany, 2008.

[41] A. Helldán, M. Kosonen, and H. Tapanainen, "The national FINDIET 2012 survey. (In Finnish, summary, figures and tables in English)," Report No. 16, National Institute for Health and Welfare, Helsinki, Finland, 2013.

[42] T. H. Totland, B. K. Melnæs, N. Lundberg-Hallén et al., A National Nutrition Survey Among Men and Women in Norway in the Age of 18-60 Years, in the Years 2010-2011, National Institute of Health, Bethesda, MD, USA, 2012.

[43] Public Health England and Food Standards Agency, National Diet and Nutrition Survey, Public Health England and Food Standards Agency, London, UK, 2014.

[44] L. Szponar, W. Sekula, M. Nelson, and R. C. Weisell, "The household food consumption and anthropometric survey in Poland," Public Health Nutrition, vol. 4, no. 5B, pp. 11831186, 2001.

[45] L. Serra-Majem, L. Ribas-Barba, G. Salvador et al., "Trends in energy and nutrient intake and risk of inadequate intakes in Catalonia, Spain (1992-2003)," Public Health Nutrition, vol. 10, pp. 1354-1367, 2007.

[46] E. Amcoff, A. Edberg, E. Barbieri et al., Riksmaten Vuxna 2010-2011. Livsmedels- Och Näringsintag Bland Vuxna I Sverige. Resultat Från Matvaneundersökningen Utförd 20102011 (Food and Nutrient Intake in Adults in Sweden 2010-2011. (In Swedish, Summary, Figures and Tables in English), Livsmedelsverket, Uppsala, Sweden, 2012. 
[47] A. Hure, A. Young, R. Smith, and C. Collins, "Diet and pregnancy status in Australian women," Public Health $\mathrm{Nu}$ trition, vol. 12, no. 6, pp. 853-861, 2009.

[48] EFSA Panel on Dietetic Products, Nutrition and Allergies, "Scientific opinion for deriving and applying dietary reference values," EFSA Journal, vol. 8, 2010.

[49] Irish Universities Nutrition Alliance (IUNA), National Adult Nutrition Survey (NANS), Irish Universities Nutrition Alliance (IUNA), Dublin, Ireland, 2011.

[50] National Academy of Sciences, Institute of Medicine, Food and Nutrition Board, Dietary Reference Intakes for Vitamin A, Vitamin K, Arsenic, Boron, Chromium, Copper; Iodine, Iron, Manganese, Molybdenum, Nickel, Silicon, Vanadium and Zinc, National Academies Press, Washington, DC, USA, 2001.

[51] L. L. Kaiser and L. Allen, "Position of the American Dietetic Association," Journal of the American Dietetic Association, vol. 102, no. 10, pp. 1479-1490, 2002.

[52] Centers for Disease Control and Prevention, "Recommendations to control and prevent iron deficiency in the United States," Morbidity and Mortality Weekly Report (MMWR), vol. 47, pp. 1-36, 1998.

[53] A. Ortiz-Andrellucchi, P. Henríquez-Sánchez, A. SánchezVillegas, L. Peña-Quintana, M. Mendez, and L. Serra-Majem, "Dietary assessment methods for micronutrient intake in infants, children and adolescents: a systematic review," British Journal of Nutrition, vol. 102, no. S1, pp. S87-S117, 2009.

[54] J. H. Brussaard, L. Johansson, and J. Kearney, "Rationale and methods of the EFCOSUM project," European Journal of Clinical Nutrition, vol. 56, no. S2, pp. S4-S7, 2002.

[55] A. Flynn, T. Hirvonen, G. B. M. Mensink et al., "Intake of selected nutrients from foods, from fortification and from supplements in various European countries," Food \& $\mathrm{Nu}$ trition Research, vol. 53, 2009.

[56] Food and Agricultural Organization of the United Nations and World Health Organization, "Human vitamin and mineral requirements," Report of a Joint FAO/WHO Expert Consultation, FAO Food and Nutrition Division, Bangkok, Thailand, 2001.

[57] Nordic Council of Ministers, "Nordic Nutrition Recommendations 2012: integrating nutrition and physical activity," Nordic Nutrition Recommendations, vol. 5, no. 11, pp. 1-3, 2008.

[58] European Food Safety Authority (EFSA), "Scientific opinion on dietary reference values for iron. EFSA Panel on Dietetic Products, Nutrition and Allergies," EFSA Journal, vol. 13, no. 10, p. 4254, 2015.

[59] European Food Safety Authority (EFSA), "Dietary reference values for nutrients," Technical Report, European Food Safety Authority (EFSA), Parma, Italy, 2017.

[60] Scientific Advisory Committee on Nutrition, Iron and Health, TSO, Dublin, Ireland, 2010.

[61] J. Lu, J. Cai, T. Ren et al., "Physiological requirements for iron in women of reproductive age assessed by the stable isotope tracer technique," Nutrition \& Metabolism, vol. 16, no. 1, p. 55, 2019.

[62] N. Milman, A. O. Agger, and O. J. Nielsen, "Iron supplementation during pregnancy. Effect on iron status markers, serum erythropoietin and human placental lactogen. A placebo controlled study in 207 Danish women," Danish Medical Bulletin, vol. 38, no. 38, pp. 471-476, 1991.

[63] V. K. Knudsen, H. S. Hansen, L. Ovesen, T. B. Mikkelsen, and S. F. Olsen, "Iron supplement use among Danish pregnant women," Public Health Nutrition, vol. 10, no. 10, pp. 1104-1110, 2007.
[64] L. R. F. Madsen, N. S. Bulow, M. Tanvig et al., "Diagnostik og behandling af jernmangel i graviditeten (Diagnostics and treatment of iron deficiency in pregnancy)," Ugeskr Laeger, vol. 180, 2018.

[65] Danish Health Authority, Diet and Dietary Supplements to Pregnant Women, Danish Health Authority, København, Denmark, 2020.

[66] European Food Safety Authority (EFSA), Food Composition Data Europe (Finland, France, Germany, Italy, Netherlands, Sweden, UK), European Food Safety Authority (EFSA), Parma, Italy, 2018. 